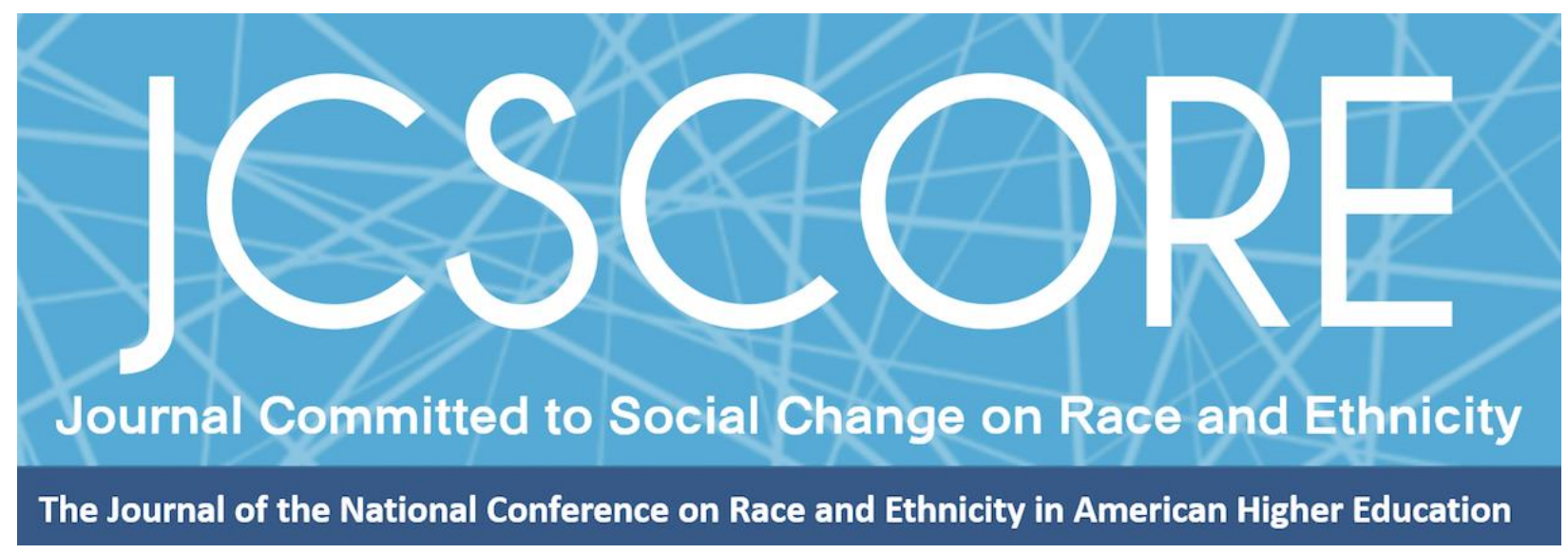

\title{
KNOW FAMILY, KNOW SELF: \\ EXPLORING THE INFLUENCE OF FAMILY ON VIETNAMESE AMERICAN COLLEGE STUDENTS' EXPERIENCES
}

Elaine N.Y. Lê

San José State University

Sonia H. Ramrakhiani

California Polytechnic State University, San Luis Obispo

Journal Committed to Social Change on Race and Ethnicity Volume 7, Issue 1| 2021

Copyright and Open Access

(C) 2021 Elaine N.Y. Lê, Sonia H. Ramrakhiani

\section{(c) (i) (-)}

This work is licensed under a Creative Commons Attribution-NonCommercial-ShareAlike 4.0 International License. Permission of the authors is required for distribution and for all derivative works, including compilations and translations. Quoting small sections of text is allowed as long as there is appropriate attribution and the article is used for non-commercial purposes.

The Journal Committed to Social Change on Race and Ethnicity (ISSN 2642-2387) is published by the National Conference on Race and Ethnicity (NCORE), a production of the University of Oklahoma, in partnership with the University of Oklahoma Libraries. 


\title{
Know Family, Know Self: Exploring the Influence of Family on Vietnamese American College Students' Experiences
}

\author{
Elaine N.Y. Lê \\ San José State University \\ Sonia H. Ramrakhiani \\ California Polytechnic State University, San Luis Obispo
}

\begin{abstract}
Much of the existing literature on Vietnamese Americans focuses on experiences of previous generations and does not capture the perspectives of the current generation of Vietnamese Americans, more specifically those who are college students. The present study examined the role of family influence on college experiences for Vietnamese American students. This study utilized qualitative methodology, analyzing data collected from semi-structured, in-person individual interviews conducted with six Vietnamese American college students (VACS) attending a large, predominantly white institution (PWI). Results from this study reveal not only how VACS construct meaning of their family influences and college experiences, but also how they come to understand their own Vietnamese American identity. Major findings from this study reveal that VACS exist between two worlds: the life of a second-generation immigrant Vietnamese American, and the life of an American college student. This article provides implications for higher education and student affairs practitioners to understand the unique experiences of this underrepresented and under-researched student population. Implications for further research are also discussed.
\end{abstract}

In 2017, 32\% of all Vietnamese Americans possessed a Bachelor's degree or higher, (Migration Policy Institute, 2018) comparable to 33.4\% of all Americans in 2016 (U.S. Census Bureau, 2017). According to the U.S. Census Bureau (2020), of all people living in the United States (U.S), 2,162,610 are comprised of Vietnamese, a steadily growing ethnic group having risen by approximately 62\% from 2000 to 2015 (Pew Research Center, 2015). Despite such data, people of Vietnamese descent, like many others of Southeast Asian descent, are aggregated into an "Other Asian" category (Yeh, 2004). However, it is important to make a clear distinction amongst social groups based 
Journal Committed to Social Change on Race and Ethnicity | Volume 7, Issue 1 | 2021

on ethnicity, nationality, and generational difference. Amongst these differences is where the interest and purpose of this present research lies-to gain a deeper understanding of how intergenerational family dynamics influence the unique experiences of Vietnamese American college students (VACS) and its implications for higher education and student affairs practitioners. The following research question guided this study: How does family influence and impact the college experiences of Vietnamese Americans? In this study, Vietnamese Americans will be used to describe those who are U.S. born, second-generation children of refugee parents, distinct from Vietnamese refugees that describe immigrants as they continue to hold that identity (Han \& Lee, 2011; Pham, 1994).

\section{Literature Review}

Previous research on Vietnamese American families focused on examining intergenerational dissonance and refugee experiences (Kibria, 1994; Kim et al., 2009; Ho \& Birman, 2010; Museus, 2013; Nguyen et al., 2011; Pyke, 2000; Tingvold et al., 2012a; Tingvold et al., 2012b), and how childhood socialization applies to this population, in which parental influence on college decision and major selection process is strong (Ma, 2009; Taub, 2008; Wartman \& Savage, 2008), sibling care is prominent (Kibria, 1994; Pyke, 2000), and extended kin support is interwoven (Tingvold et al., 2012a; Tingvold et al., 2012b). However, there is a lack of research highlighting the current experiences of VACS that incorporates all of these facets. In examining the literature on this topic, the researchers sought to gain a deeper understanding of VACS' experiences in connection to parent-child relationships, household socioeconomic status, family structure and family time, and the potential culture clashes that may 
Journal Committed to Social Change on Race and Ethnicity | Volume 7, Issue 1 | 2021

result. Below is a summary of the existing literature that examines these factors individually.

\section{Parent-Child Relationships}

While there are current studies that examine Asian American student experiences, they do not account for Southeast Asian Americans with war legacies such as Vietnamese Americans. Existing research on family influence and Vietnamese American students is outdated, focusing on experiences of first-generation immigrants and on parent-child relationships (Nguyen et al., 2011; Nguyen \& Cheung, 2009). Vietnamese American children struggle between reconciling filial piety, a collectivist practice that emphasizes respect, devotion, and commitment to ancestors and elders (Museus, 2013), with American norms and values that prioritize individualist practices. Through their parents' consistent reminders, Vietnamese American students are made aware of their privileges and opportunities in light of their family's sacrifices during wartime (Nguyen et al., 2011; Nguyen \& Cheung, 2009). Furthermore, many Vietnamese Americans endure the pressure to fulfill family obligations and expectations (Trieu, 2016), especially the duty to care for elder parents as they progress into older age.

Vietnamese American students experience family conflict in the form of acculturation gaps between their parents and themselves (Ho \& Birman, 2010; Kim et al., 2009). They also perceive their parents' parenting styles as authoritarian and authoritative (Nguyen \& Cheung, 2009), which may be associated with symptoms for depression and anxiety (Nguyen et al., 2011). Beyond mental health, researchers have also investigated the effects of parent-child relationships on Asian American college 
Journal Committed to Social Change on Race and Ethnicity | Volume 7, Issue 1 | 2021

students in comparison to European American college students, reporting an association between parent-children's relationships, self-efficacy and academic performance (Yuan et al., 2016).

\section{Collectivism Versus Individualism}

VACS may face challenges in adjusting from the collectivist home environment to the individualist college setting. Many are the first in their family to attend college, thus experiencing pressure to perform and meet their parents' expectations of success (Trieu, 2016). These students may also experience internal role conflict, mitigating values and practices that privilege the harmony of a social group with values and practices that privilege the benefit of the individual (Ho \& Birman, 2010; Pham, 1994). In fact, they reportedly experience higher depressive symptoms compared to other Asian college students (Han et al., 2007). According to a study conducted by Billing et al. (2014), individuals living in individualist cultures reported feeling guilty about sacrificing family time for work, while individuals living in collectivist cultures may justify that time allocation by framing it as a sacrificial benefit for the family. Individuals who prioritize collectivist values may have greater intentions to leave the workspace in the presence of work-family conflict (Billing et al., 2014).

Furthermore, Vietnamese American households practice patchworking, highlighting the ways in which domestic family members share both economic and educational resources in order to benefit the household as a whole (Kibria, 1994; Pyke, 2000). These household structures uphold collectivist family ideologies and illustrate immigrant social and economic adaptation strategies. Different household compositions based upon gender and age diversity suggest potential benefits of heterogenous 
Journal Committed to Social Change on Race and Ethnicity | Volume 7, Issue 1 | 2021

households (Kibria, 1994). However, many Vietnamese Americans are growing to prefer individualistic economic affairs rather than collectivist familial activities (Pham, 1994). As a result, they experience intricate challenges in reconciling collectivist household ideologies with external individualistic desires and goals. In light of this conflict and shift, it is important to understand how values within the private and public spheres affect VACS during their undergraduate career.

In summary, existing studies examined effects of parent-child relationships on child mental health (Han \& Lee, 2011), academic performance and self-efficacy (Yuan et al., 2016), constraints between collectivism and individualism (Billing et al., 2014), and intergenerational cultural dissonance (Palmer \& Maramba, 2015; Pham, 1994). However, none of the research has comprehensively examined all of these factors in conjunction with student development.

\section{Theoretical Framework}

There are several student development theories that could potentially address the cognitive, interpersonal, psychosocial (intrapersonal), and ecological domains of this study. However, these theories alone are insufficient in capturing the psychosocial development of VACS. For this reason, the researchers have outlined and proposed the marriage of two theories, student development theory (Chickering \& Reisser, 1993) and psychosocial development theory (Erikson, 1963).

\section{Student Development Theory}

To better understand the experiences of VACS from a developmental lens, the researchers employed Chickering and Reisser's (1993) theory suggesting that students move through various complex and interrelated vectors in a non-sequential order, 
Journal Committed to Social Change on Race and Ethnicity | Volume 7, Issue 1 | 2021

developing greater stability and intellectual complexity as they traverse each vector. At the midway point of student development lies Vector III: Moving Through Autonomy

Towards Interdependence, which encompasses the development of emotional independence, instrumental independence, and interdependence. Students begin to develop emotional independence as they disengage from parents, seek support from peers and role models, and appreciate time with others and time alone. Instrumental independence encompasses self-sufficiency marked by the ability to exit one environment and function well in another. Students moving toward interdependence gain an understanding about reciprocity, compromise, sacrifice, consensus, and a commitment to community welfare. VACS' experiences in establishing autonomy and interdependence may be influenced by factors of family commitment (Pyke, 2000) and family support (Chhuon \& Hudley, 2008).

\section{Psychosocial Development Theory}

In conjunction with student development theory, the researchers have utilized Erikson's (1963) eight stages in order to understand the psychosocial development of VACS both as second-generation immigrants and as college students. Within each stage, Erikson (1963) proposed that individuals may experience psychosocial crises as psychological needs and societal demands intersect, resulting in positive or negative impacts on personality development that inhibit or mitigate movement towards a previous or advanced stage. The fifth stage 'identity versus role confusion,' associated with ages 13 to 19 , describes a process in which individuals experience a critical transition from childhood to adulthood, gaining a greater sense of independence and visualizing their future within the scope of relationships, career, and long-term goals 
Journal Committed to Social Change on Race and Ethnicity | Volume 7, Issue 1 | 2021

(Erikson, 1963). Essentially, individuals begin to understand the different roles that they will assume as adults. However, individuals may also experience role confusion or identity crisis within this stage if different roles that they assume in different contexts are in conflict, or if they fail to develop a consistent self-identity (Erikson, 1963).

In comparing the two theories, Erikson's (1963) theory explores the potential vehicles that facilitate identity congruence or identity crisis experienced as individuals navigate adolescence, whereas Chickering and Reisser's (1993) theory investigates the mechanisms by which college students, young adults, acquire autonomy through experiences of independence and interdependence. While Erikson's (1963) theory explores congruence and conflict as an individual negotiates an internal self with external selves, Chickering and Reisser's (1993) theory highlights the negotiation an individual agrees upon internally in order to interact with the external social world. Although Erikson's (1963) theory provides a framework that scholars and practitioners may apply in understanding adolescent and student development, it remains critiqued in excluding the unique experiences of role confusion that result not only from the strain between individual desires and societal expectations, but also from the intersectionality of an individual's social identities (Sneed et al., 2006). Accordingly, the researchers have utilized both theories proposed by Chickering and Reisser (1993) and Erikson (1963) in exploring how cultural identity and familial relationships influence experiences of VACS.

\section{Methods}

Guided by the purpose of this study, qualitative methodology was selected as it enabled the researchers to highlight the individual essence, experiences, perspectives, 
Journal Committed to Social Change on Race and Ethnicity | Volume 7, Issue 1 | 2021

and unique stories of VACS (Andrews et al., 2008; Creswell, 2014; Hays \& Singh, 2012). This study was conducted from a social constructivist paradigm through examining the participants' voices regarding their experiences as college students coming from Vietnamese households and families. Semi-structured interviews were conducted using a narrative inquiry approach, grounded in interpretive hermeneutics and phenomenology, involving gathering narratives and examining the meanings that people ascribe to their experiences (Trahar, 2009). As Pinnegar and Danes (2007) suggested, "Narrative inquiry embraces narrative as both the method and the phenomena of study" (p. 4). Thus, the narrative inquiry tradition coupled with a constructivist paradigm enabled the researchers to explore and examine VACS' experiences, uplifting participants' voices in order to understand what it means to navigate the intersection of being a college student and being a Vietnamese American. Context and Participants

Participants were recruited through convenience sampling. After securing IRB approval, the primary researcher conducted outreach to various campus organizations and communities, targeting Asian American-focused student organizations at a large, predominantly white institution (PWI). The primary researcher conducted brief outreach presentations to various groups, yielding 6 male-identifying participants who entered college as first-time freshmen. All participants were recruited through a cultural student organization that focuses on Vietnamese Americans and another Southeast Asian population. Participants were given the option of choosing their own pseudonym. Participant demographics are listed in Table 1. 
Journal Committed to Social Change on Race and Ethnicity | Volume 7, Issue 1 | 2021

Table 1. Participant Demographic Information

\begin{tabular}{|l|l|l|l|l|l|}
\hline Pseudonym & Age & Socioeconomic Status & Year in College & Major & Birth Order \\
\hline Aaron & 18 & Upper Middle Class & Freshman & Statistics & First Born \\
\hline Blue & 18 & Middle Class & Freshman & Biology & First Born \\
\hline Minh Son & 19 & Upper Middle Class & Sophomore & Business & $\begin{array}{l}\text { Second Born } \\
\text { (Last Born) }\end{array}$ \\
\hline Joe & 20 & Low-Income & Sophomore & Nutrition & $\begin{array}{l}\text { Third Born } \\
\text { (Last Born) }\end{array}$ \\
\hline Hien & 20 & Middle Class & Sophomore & Engineering & First Born \\
\hline Daniel Bao & 21 & Middle Class & Senior & Engineering & Only Child \\
\hline
\end{tabular}

\section{Researcher Positionality}

Within any qualitative study, it is imperative to discuss how the positionality of the researchers impact data collection, analysis, and interpretation (Jones et al., 2006). As people of color, the researchers shared a vested interest in increasing awareness and highlighting the voices of this underrepresented, under-researched population in higher education. The primary researcher shared more similarities with the population under investigation as she identified as a first-generation, low-income, cisgender female, VACS in a higher education/student affairs graduate program. It is the social identities and lived experiences of the primary researcher that initiated academic inquiry into the narratives of others who share similar ethnic, cultural, and intergenerational backgrounds. The primary researcher's identities facilitated her entrée into spaces where VACS gather and encouraged responsive rapport-building. Additionally, similarities shared between the primary researcher and participants facilitated a data collection process and analysis informed by an enriched perspective that cannot be obtained solely through existing literature or observation. However, this unique perspective could also potentially introduce bias into the study, ultimately resulting in an 
Journal Committed to Social Change on Race and Ethnicity | Volume 7, Issue 1 | 2021

unintentional reinterpretation of the data, rather than an intentional interpretation of the participants' individual experiences.

To further minimize the influence of researcher bias, the primary researcher engaged in reflexivity all throughout and secured the support of a second researcher, who identified as a first-generation, Indian immigrant, cisgender female that served as a faculty member within the same higher education/student affairs graduate program as the primary researcher. Although the second author also shared some identities with the participants and the primary researcher, she was also able to maintain objectivity as she did not participate in the interviewing process. Both researchers independently coded the data and met consistently to discuss differences in perceived codes (Hays \& Singh, 2012). Insights from these meetings allowed the researchers to reduce bias in data analysis. This study also benefited from the production of this research team as it facilitated the sharing of participants' enriched narratives while also ensuring that their contributions were interpreted properly to honor their original meanings.

\section{Data Collection}

The primary source for data collection was gathered through demographic questionnaire responses and individual interviews with participants. In efforts to supplement the individual interviews, participants were asked to complete a demographic questionnaire that asked for information related to age, gender, socioeconomic status/class, location of origin, campus and community involvement, and family birth order. Participants were asked a series of questions during in-person individual, semi-structured interviews ranging from 35-60 minutes. The interview questions focused on pre-college experiences, family dynamics, and college 
Journal Committed to Social Change on Race and Ethnicity | Volume 7, Issue 1 | 2021

experiences. For example, some of these questions included, "In what ways do you think your college experiences were shaped by your relationship with your family, if at all?" and "How do you think that your relationship with your family has changed since starting college, if at all?"

\section{Trustworthiness Strategies}

In addition to engaging in reflexive practices and enlisting a co-researcher, the primary researcher also engaged in participant checks in order to gauge the alignment between the researchers' interpretations and the participants' responses (Hays \& Singh, 2012, p. 146). For example, participants used the term "Asian" and "Asian American" to describe their own positionalities and performative experiences within different racial groups. Following the interviews, the primary researcher engaged in member-checking by contacting each participant to clarify the meaning of the terms "Asian" and "Asian American" to understand specific instances in which participants were referring to Asians, Asian Americans, East Asian Americans, and Vietnamese Americans.

Additionally, transcripts were provided to participants who were given the opportunity to provide any changes needed in order to reflect their thoughts, feelings, attitudes, and experiences more accurately.

\section{Data Analysis}

The researchers utilized an 8-step process of data analysis outlined by Hays and Singh (2012): reduce data, collect data, memo and summarize, organize text, code, identify themes and patterns, create a codebook, and develop the main narrative. The researchers analyzed the data via a three-cycle coding process (Saldaña, 2009). First, the researchers individually coded two transcripts, each paying close attention to the 
Journal Committed to Social Change on Race and Ethnicity | Volume 7, Issue 1 | 2021

data. After the first round, they discussed the initial codes and developed a codebook. They continued coding two transcripts at a time and meeting for consensus coding in order to discuss and enter emerging codes and patterns into the codebook. During this process of consensus coding, each researcher shared their own set of codes and discussed any discrepancies resulting from individual biases. In addition, they discussed and modified some codes to better reflect participants' experiences. Finally, they collapsed the codes and created a final consensus codebook, which identified overarching themes that guided the initial narrative development. Following are the findings from the study.

\section{Findings}

Three themes emerged from participants' narratives: family dynamics, family culture, and sociocultural identity. Various sub-themes were identified within each theme: parent-child relationship, sibling relationships, expectations, war legacy, cultural identities, assimilation and acculturation, sense of belonging, and cultural adjustment.

\section{Family Dynamics}

Participants understood and experienced their families through various constructs dealing with parent-child relationship and sibling relationships, each described in some detail below.

\section{Parent-Child Relationships}

Parent-child relationships were a significant subtheme and were discussed in various ways relating to parental support and gender constructs. Five participants discussed their family dynamics in terms of support, specifically focusing on the basic needs that their parents provided for them. Four participants discussed a family culture 
Journal Committed to Social Change on Race and Ethnicity | Volume 7, Issue 1 | 2021

of support wherein parents fulfilled basic needs, and siblings or cousins fulfilled emotional needs. While VACS look towards their parents for a degree of support, there are distinct branches within their familial support system. Minh Son expressed:

I mean they're pretty supportive overall. In terms of [parental] emotional support, it's not huge. Me and my sister had each other for emotional support and so our parents are good at giving us career advice, school advice, obviously providing for us financially. But figuring out how we feel about things? That's how me and my sister bond.

Participants also spoke about their parents' impact on explicit and implicit aspects of their lives. Although all participants expressed valuing gender egalitarianism, some of their responses reflected a gendered dichotomy between their mothers' and fathers' roles, personalities, and relationships within their families. Daniel Bao explained:

My mom is a hairstylist, so pretty typical Asian mom... She works part-time. She used to work full-time until I was born. And then she worked part-time to take care of me. My dad is an associate engineer at an engineering company, so he's the breadwinner. He brings home the money... [But] Gender roles weren't a real big thing for me.

Subsequently, respondents discussed their parents' awareness of gender discrimination and intent to combat the negative impacts that it may have on their children. Minh Son shared:

My dad was always supportive of my sister doing whatever she wanted. Whatever she took interest in, he would support her a lot even if it wasn't girly... I'm really close to my mom. I think it's just 'cause my dad tried to spend a lot of time with my sister and made sure she didn't get down being discriminated against because she's a woman.

Throughout the interviews, gender was revealed as an integral facet of parent-child relationships contributing to VACS' overall family dynamics. While traditional gender beliefs continue to persist in VACS' reflections on their parents, participants shared explicit individual and familial sentiments congruent with gender egalitarianism, 
Journal Committed to Social Change on Race and Ethnicity | Volume 7, Issue 1 | 2021

underlining a shift in traditional Vietnamese beliefs and values and its potential impacts on the outlook and life chances of present and future generations.

\section{Sibling Relationships}

In exploring family dynamics, five of the six participants discussed the importance of their sibling relationships and birth order. Three participants identified as the firstborn, eldest brother with subsequent roles and responsibilities. In describing his experience, Blue shared:

I've come to accept that I play that human shield of older brother role, so things that I couldn't do that they [younger brother and sister] can do, I tell them all the time, 'Don't take it for granted. These things you get to do, I didn't get to do when I was your age.'

Blue emphasized that the eldest child in a Vietnamese American family is tasked with the responsibility to remind younger siblings to practice gratitude-to realize that rights given to them by their parents were once privileges unafforded to their eldest sibling, as shaped by traditional Vietnamese beliefs. Through challenging his parents' perspectives, Blue did not succeed in gaining privileges for himself, though he eventually paved the way for opportunities which were granted to his younger siblings. As the first-born son, Blue shared that this responsibility to younger siblings shaped his character, ultimately influencing his decision to pursue a leadership role within a Vietnamese and Southeast Asian American (VSSA) student organization on campus.

Two respondents who identified as the youngest sibling were also assigned different roles within their families. In reflecting on his experience, Joe expressed:

I'm like 12 and 14 years younger than my brother and sister so I was like more of the baby of the family... I didn't really have a role in my family until [we moved to a new city]. It was just me and my dad and my mom. During that time, I was their 
translator. I paid their bills online because they weren't literate with technology and stuff like that... I was kind of like a sponge for their anxieties and their stresses.

Joe's experience illustrates that of the last-born child serving a caretaking role for his immigrant parents, contributing to his development of independence. While older adult siblings have moved forward in pursuit of their individual lives outside of the household, the youngest sibling assumes the responsibility of supporting their parents through bridging significant language gaps. Evidently, birth order, sibling age gaps, and division of family care comprise sibling relationships, contributing to VACS' overall family dynamics.

\section{Family Culture}

Respondents discussed culture within their own families, highlighted within the following two subthemes: expectations and war legacy.

\section{Expectations}

Three respondents discussed familial expectations placed upon them within academics and beyond, while also highlighting the significance of strong family communication. Daniel Bao explained:

Grades were a big deal, they still are obviously. I can't be going home with anything below a 3.0 [GPA]... But I think they're pretty aware of mental health awareness issues. They don't explicitly say it, but they'll be like "Don't get too stressed out if you're not getting those grades."

Aaron also expressed:

[Junior year was] one of the biggest years in high school in terms of grades and pressure and all that [due to college apps]. I think that was the year [my parents and I] had a lot of fights... I think at least when I look back on it, it was at least important for me that it didn't break us. We had a strong relationship and we always talked about that afterwards. 
Journal Committed to Social Change on Race and Ethnicity | Volume 7, Issue 1 | 2021

Daniel and Aaron's experiences highlight a family culture that values academic and career success, sure expectations that have generated conflict between their parents and themselves. However, it appears that Vietnamese parents are beginning to acknowledge the negative impacts of stress and the importance of maintaining a strong relationship with their children. While they continue to hold high expectations for education and career success, Vietnamese parents are acknowledging the importance of VACS' overall wellbeing.

When asked about their college application experience, all six respondents emphasized that attending college was automatically expected—by their families, their peers, and themselves. All respondents shared a prominent college-going expectation placed upon them by their family, peers, and environment Aaron shared:

I think it was pretty expected of me. I know that there's definitely a lot of people who, either they're not expected to, or there's no pressure for them... Kind of like the culture and society that I grew up in, I grew up in the middle of the Bay Area in the Silicon Valley, so it was definitely expected of me to go.

As a result of their families' histories, all six participants shared that they were internally motivated to attend college, earn a quality education, and advance towards a fulfilling career. Joe expressed:

The biggest responsibility I have is to work hard 'cause of my family's current situation. Being first-generation, I have this drive that to just excel and achieve and that's one of the biggest things. Other than that, there's not much. My parents gave me the independence and they have to trust that l'll be able to excel and do really well.

Beyond the expectation to earn a higher education, two respondents also discussed the cultural expectation to care for elder family members, namely aging parents. Daniel Bao illuminated: 
It's definitely expected of their kid to take care of their parent when they're older... it is expected that I am there to meet the expectation because I do think it's quite important-that they did raise me as a kid and there is that obligation of duty and responsibility for them when they're older.

Participants' insights reveal that they are motivated to succeed within their college education and future careers in order to compensate for their parents' efforts, taking advantage of opportunities that their parents were not afforded. In addition to academic and career expectations, the family culture of VACS is also largely shaped by a strong sense of respect and responsibility for elders. Evidently, VACS' college-going decisions have been shaped not only by their peers but also by a family culture that values higher education, career success, and family repayment.

\section{War Legacy}

All six participants expressed profound struggles that their parents and older family members faced in fleeing Vietnam, seeking refuge in a foreign country, and encountering an excess of insecurities and unknowns. Although all participants did not directly endure the Vietnam War, they all shared an awareness of the ways in which it has impacted their families and in turn, themselves. Hien explained:

As I got older, I started to realize more of the things my family went through.

They started telling me more stories of how they came here after the war and it just started to make me feel a lot more humble because I was just blind to all this, I didn't need to worry about it.

Blue also discussed important lessons gained from his parents, resulting from the war:

They would tell us like, 'Yeah this is what happened to us during the war...' They taught me to live in the moment... don't worry about the future and what it can hold 'cause sometimes like the future might not be what you expect. Like, certain things happen, there's nothing you can do about it... just go with what's going on in the world. 
Journal Committed to Social Change on Race and Ethnicity | Volume 7, Issue 1 | 2021

The legacy of the Vietnam War continues to manifest itself within the family culture of VACS, serving as a reminder of the past, testament to the present, and hope towards the future. This reminder and tribute to their families' struggles, histories, and triumphs enrich VACS' understanding of who they are, who they wish to be, and who they are becoming.

\section{Sociocultural Identity}

Exploration of sociocultural identity and personal growth was evident throughout participants' responses, focusing on the following key components: cultural identities, assimilation and acculturation, sense of belonging, and cultural adjustment.

\section{Cultural Identities}

All six participants reflected on the differences between opportunities granted to their parents and themselves, acknowledging an intergenerational gap in privilege. Hien noted, "Growing up, they were immigrants. So, their number one priority was they had to survive in a country before finding any like, self-actualization or any of that." Hien expressed both remorse and respect for his parents' struggles, further deepening his gratitude towards seeking purpose and fulfillment beyond basic needs. Through acknowledging history, VACS not only gain a greater respect and appreciation for their parents, but also a deeper understanding of what it means to be Vietnamese American.

Three participants discussed how their parents' limited opportunities underscored their desire to encourage and witness their children's successes. Participants' educational and career decisions were guided by this aspiration for compensation and justification. Minh Son expressed: 
Journal Committed to Social Change on Race and Ethnicity | Volume 7, Issue 1 | 2021

My dad grew up very low income, so he didn't have a chance to do a lot of things he was passionate about, so I think he just wants me and my sister to do that 'cause he doesn't want us to waste our chance.

Aaron emphasized the importance of exposure and representation in forming his own understanding of what it means to be Vietnamese American:

[In college] I have like no access just to anything that's comforting or that reminds me of my roots. I am glad though that recently I have been able to reconnect to it. It's thanks to a lot of social media influences-like I would be on YouTube and watch like, people like the Fung Bros, Richie Lee, Lynda Dee Productions, Wong Fu. A lot of them helped me to understand that like 'Oh it's okay to embrace your heritage' and all that.

While participants' cultural identities were largely shaped by that of their parents, they revealed a gap in defining the Vietnamese American identity for themselves. Within their family households, VACS may come to understand what it means to be Vietnamese American through honoring their parents' histories of refuge from war. However, as they leave home and attend college, some VACS also seek popular media representations as guiding references towards their developing and deepening cultural identity. Stories pieced together by their parents and by social media figures who share similar generational experiences contribute to VACS' understanding of their cultural identity, a key facet in their overall sociocultural identity.

\section{Assimilation and Acculturation}

Participants shared their experiences in identity exploration and navigating lost culture through the processes of assimilation and acculturation, highlighting how their experiences of assimilation greatly differed from their parents' experiences of assimilation and/or acculturation. All six participants highlighted these differences and the impacts that they had on their identity. Participants discussed the importance of representation and community in understanding their heritage. Aaron explained: 
I decided to research about... kids of immigrants, specifically from Vietnam [and] what their experiences are growing up. And I think that really opened my eyesseeing my feelings put on paper by an academic... that was definitely something that helped me later on because now I definitely embrace that side of me... now having matured, I can embrace that side of me.

Regardless of the levels at which respondents described the experiences of assimilation or acculturation, all underlined some intergenerational challenges that remain. Aaron described:

I think [the separation between what parents want and what teenagers want] was more pronounced especially being the son of immigrants, that's definitely a factor. And even though my mom was definitely Americanized, [she] was always definitely trying to remind me of my own Vietnamese culture... I know that wasn't something I really associated with because my reasoning was, 'Oh, I was born here. I was raised here.'

Three respondents discussed the loss of language in describing their own experiences of assimilation and intergenerational differences. Minh Son shared:

We don't speak Vietnamese to each other. Me and my sister used to be able to speak Vietnamese fluently 'cause when we were younger, we spent a lot of time with our grandparents because both of our parents work full time. But once I went to school... I couldn't speak too much English, so my parents just spoke English to us at home so we could learn it quicker.

Respondents also revealed the contest between traditional values and modern

practices, with the themes of strict rules and caring for elders resonating most amongst all. Three participants expressed that their parents enforced strict rules, especially as it related to leisure time and socializing with friends, which contributed to challenges that they faced growing up. Strict rules regarding curfew were interpreted as an intergenerational practice. Blue underlined:

Going out was a little hard for me... the way [my parents] were raised it was just like, 'Okay, you can't really go out. You have a curfew. You can't go out every so often. You can't just go out whenever you want, or just leave the house and say see you later. You need to ask permission.' Like, you need to tell them where you 
Journal Committed to Social Change on Race and Ethnicity | Volume 7, Issue 1 | 2021

are at all times... The way they were raised, they had curfews and couldn't go out very often.

Participants revealed the significant role that assimilation and acculturation served in the formation of their sociocultural identities. In discussing their families' experiences of assimilation and acculturation, participants underscored fragments of lost culture including language and customs, seeking a deeper layer of identity through literature rather than family conversation. In understanding their Vietnamese ethnic identity and American national identity, VACS experience cultural dissonance-while they are interested in gaining a richer understanding of Vietnamese culture, they also seek freedoms associated with a more assimilated culture reflecting individualist family values.

\section{Sense of Belonging}

Four participants discussed the significance that Vietnamese student organizations served in contributing to their sense of belonging at a PWI. Joe explained:

[My parents] have an idea of this [VSSA] club that helps me feel at home. 'Cause they know. I told them about the problems I had like with the diversity and the, just the number of white students and how they made me uncomfortable. So, they understand that and then they see that the clubs I'm in, they help me get through that.

It was not until they joined specific on-campus cultural organizations that participants of

this study began to develop a sense of belonging at a PWI. Daniel Bao shared:

First year, first quarter is where I struggled to find friends and I wasn't sure where I belonged... I did join the [Southeast Asian cultural dance] team my freshman year fall quarter. I want to say the quarter after, [Southeast Asian cultural dance] started picking up and I got more involved with that. I got closer to a lot of other members... I started cementing myself like, 'Here's where the clubs are, the clubs I go to, here's my friend group.'

Respondents highlighted not only the importance of cultural student organizations, 
Journal Committed to Social Change on Race and Ethnicity | Volume 7, Issue 1 | 2021

but also the acknowledgement of such groups on campus. While cultural organizations create and maintain opportunities for community building, it is only within those spaces that minoritized groups on campus may reliably gain a sense of belonging. As such, it is important for the campus community at large to recognize these cultural organizations and community spaces in order to contribute to a greater sense of belonging that transgresses the margins. Minh Son expressed:

I think having [VSSA student organization] is helpful, but someone had to create that. I think helping people feel more included by promoting these cultural clubs more "cause a lot of the promotion we have to do for [VSSA student organization] is on our own.

Integral to VACS' exploration of sociocultural identity is gaining a sense of belonging through building community. Within community spaces such as the VSSA student organization, VACS work individually and collectively towards understanding the Vietnamese American identity. However, while the creation and maintenance of intentional community spaces benefit VACS, they would feel a greater sense of belonging through receiving support and recognition by the larger campus community.

\section{Cultural Adjustment}

All six participants described challenges that they faced due to their Vietnamese American identity, an ethnically minoritized population on campus. Within the college setting, participants realized and experienced the magnitude at which they are different from others due to their ethnic background. While respondents expressed continuous efforts towards understanding their Vietnamese American identity, they also highlighted challenges in transitioning from their ethnically diverse hometowns to a PWI. Joe explained: 
Journal Committed to Social Change on Race and Ethnicity | Volume 7, Issue 1 | 2021

When I came here it was kinda a shock because it was a PWI. I wasn't used to it and every time I was in class, I felt like everybody was looking at me and I had this kinda stereotype threat where I was like, 'Oh, I wasn't supposed to be here. I'm gonna do bad or worse because I was just the odd one out.'

VACS' experiences as a minoritized population at a PWI may have negative impacts not only on their academics and attendance but also their sense of worth and overall wellbeing. Through adjusting to a campus demographic and culture dominated by whiteness, VACS' sociocultural identities are further demarcated.

All six participants also expressed a desire to have more representation. Hien suggested:

Shedding light on the fact that we don't have the same opportunities would be good... not ignoring what the Vietnamese War has done to us... have more talks and understand what happened. Being invested in our culture and showing interest would do a lot to get more Vietnamese Americans in wanting to continue in the American education system by showing 'We care where you came from, we care about your experiences.'

Hien's response underlines how cultural adjustment contributes to VACS' sociocultural identity, shaped not only by their ethnic and cultural background but also their ecological contexts. In reflecting on challenges that they faced in adjusting to a PWI, participants shared their hopes for higher education: recognizing the unique complexities of the Vietnamese American identity beyond the pan-Asian ethnic category, acknowledging the history and legacy of the war, and celebrating their culture through past and present. Rather than assuming the individual responsibility of adjusting from one cultural context to another, participants would feel more supported within higher education if institutions were fundamentally designed towards inclusion.

\section{Discussion}


Journal Committed to Social Change on Race and Ethnicity | Volume 7, Issue 1 | 2021

The themes that emerged from this study not only serve as a starting point on uncovering the impact of family and culture but also emphasize the significant role of both influences on VACS' experiences. Evidently, parent-child relationships play a significant role in academic outcomes and self-efficacy (Yuan et al., 2016). Based on this study, younger generations continue to experience parent-child intergenerational dissonance, the mechanism by which disagreements occur, emphasized in areas that differ from the preceding generation. Congruent with Erikson's theory (1963), participants reported gaining a sense of autonomy and independence upon entering college and expressed that they are better able to confide in their parents with concerns related to academics, extracurriculars, and careers. Subsequently, they are able to seek emotional support from parents, siblings, cousins, or peers (Fu \& Hazel, 2014), and may even view them as "caring agents" (Palmer \& Maramba, 2015, p. 50).

Participants expressed general satisfaction in their relationships with their parents, suggesting variation from intergenerational conflict and dissonance that was once reported (Nguyen \& Cheung, 2009; Nguyen et al., 2011). Consistent with the theoretical framework of this study, participants experienced parent-child intergenerational gaps, no longer marked by conflicting values between individual wellbeing and collective welfare, but instead nuanced differences in degrees of acculturation and assimilation (Ho \& Birman, 2010; Kim et al., 2009). While participants highlighted the significance of parental support in obtaining a higher education, gaps in cultural meanings and experiences still exist between their parents and themselves.

Simultaneously, all participants of this study illustrated their own collectivist values through expressing intent to eventually provide financial support to their families, 
Journal Committed to Social Change on Race and Ethnicity | Volume 7, Issue 1 | 2021

reflecting the value and practice of repayment engrained within the family culture (Trieu, 2016). Consistent with Chickering and Reisser's theory (1993), while participants received support from their families in developing and strengthening their own independence, autonomy, and decision-making processes expedited through their college experiences, they continued to value respect for their family and elders. Participants' responses revealed that outward practices of filial piety (Museus, 2013) are shifting within younger generations of Vietnamese Americans, though loyalty and respect towards the family remain. Similar to findings from Trieu's (2016) study, in which 50 Vietnamese Americans were interviewed regarding familial obligations, the researchers found that participants highlighted the ways in which their coming-of-age, education journeys, and career paths were impacted by their respect for family rules and anticipation of elder care.

Many VACS experience the war diaspora in a fundamentally different manner than that of their parents who directly witnessed and survived the war (Pham, 1994). Outside of the scant Westernized war narratives that they are taught within public education, many VACS learn about the deeper ramifications of the war through collecting fragments of informal oral histories passed down by their older relatives in conjunction with seeking culturally and socially relevant literature and media as supplementation. In congruence with Chickering and Reisser's theory (1993), participants expressed an understanding of the war tragedies, scarce opportunities, and life sacrifices that their parents faced, underlining the privileges that VACS possess such as the ability to pursue a higher education without worry over securing basic needs 
Journal Committed to Social Change on Race and Ethnicity | Volume 7, Issue 1 | 2021

and safety. Subsequently, they conveyed a desire to learn more about their own history and heritage to better understand their parents and in turn, themselves.

Previous research on cultural identity among VACS focused on the negative effects of racial discrimination (Lam, 2007). However, this present study highlighted the impact of family culture and campus culture on participants' experiences (Sneed et al., 2006). Similar to the experiences of Cambodian American students in Chhuon and Hudley's study (2008), participants reported struggling with adjusting to college and gaining a sense of belonging, yet successfully found support through direct participation in cultural organizations on campus. As underlined by Libarios et al. (2018), there are unique differences within the Asian American community_ unseen within the panethnic Asian American identity, many underrepresented, minoritized Asian Americans feel marginalized, invisible, and isolated. In response, participants in the current study sought representation for their community, while also seeking opportunities to celebrate their culture and heritage.

Overall, the findings from this study are consistent with the third vector of Chickering and Reisser's (1993) theory suggesting that students move from autonomy towards interdependence, maintaining their emotional independence while subsequently remaining interdependent on their parents, reflecting the collectivist culture in which they are rooted. Congruent with Erikson's fifth stage (1963), participants persisted through developing their own sense of self and personal identity through exploring their own values, beliefs, and goals (Erikson, 1963).

Implications for Practice 
Journal Committed to Social Change on Race and Ethnicity | Volume 7, Issue 1 | 2021

This study provides several implications for culturally responsive practices within higher education and student affairs. Through appreciating student narratives, higher education and student affairs practitioners can better contextualize experiences not only pertaining to the Vietnamese American demographic, but also other ethnically minoritized student groups from various diasporic backgrounds, in order to better serve and support them (Libarios et al., 2018). The results from this study provide suggestions for practitioners and advocates to better understand this population from developmental, ecological, and multicultural perspectives.

Higher education and student affairs practitioners may better serve these students by understanding how cultural contexts impact their own individual development and growth (Libarios et al., 2018). While practitioners may employ a student-centered approach informed by an understanding that student development involves seeking support from peers and mentors and separating from parents (Chickering \& Reisser, 1993), their approach may be further enriched by adopting a multicultural perspective that privileges collectivist values impacting different student demographics amidst individualistic contexts. More specifically, practitioners may better support VACS by understanding how their cultural and familial contexts significantly impact their experiences of gaining and practicing independence (Palmer \& Maramba, 2015). This approach may be applied to all practitioner-to-student interactions to create a more inclusive and empathic environment of support.

Subsequently, practitioners may employ a multicultural perspective in order to acknowledge, rather than assume, the various degrees and experiences of acculturation and assimilation within each racial or ethnic group. Some participants of 
Journal Committed to Social Change on Race and Ethnicity | Volume 7, Issue 1 | 2021

this study came to understand themselves as fully "Americanized", whereas others found themselves as "half-traditional, half-Americanized"; complex terms that carry distinct meanings for each individual. Although VACS share common experiences in identity exploration, it is important for practitioners to acknowledge each individual's understanding and interpretation as it is true to them. While these students' experiences may appear similar to the overarching Asian American experience, overgeneralizations undermine the distinct complexities of each ethnic and diasporic group, erasing the unique experiences of each group and individual (Libarios et al., 2018).

Participants reported value in gaining a sense of belonging through membership within a Vietnamese American and Southeast Asian American student organization on campus. Practitioners may better advocate for a more inclusive level of representation for all minoritized student populations through allocating equitable funding and resources for these types of cultural organizations (Libarios et al., 2018; Palmer \& Maramba, 2015). The primary researcher engaged in other investigative strategies that were omitted from the formal research methods in order to better understand organization membership and sense of belonging. Through attending several meetings and presenting content that showcased sociohistorical context for both ethnic cultures, the researcher observed that many members expressed value and interest in such programming (Palmer \& Maramba, 2015). Accordingly, practitioners may create more inclusive spaces that encourage holistic student development from a multicultural perspective, advocating for affinity groups that create opportunities for deeper exploration of heritage and history, aligning with research that underlines its importance and efficacy (Bentley-Edwards et al., 2016). 
Journal Committed to Social Change on Race and Ethnicity | Volume 7, Issue 1 | 2021

Culture remains a multi-faceted, complex phenomenon that continues to inherently complicate itself as a human experience. Within the U.S., culture is often regarded as a deficit and individuals are encouraged to assimilate to the larger, dominant culture that privileges Western ideals and historical context. Accordingly, it is imperative that higher education and student affairs practitioners contribute to widening the larger narrative to include, encourage, and celebrate culture (Libario et al., 2018). Although all participants possessed sparse knowledge about the Vietnam War, all expressed an interest in learning more about their heritage, including a deeper history of their family's home country, its people, and the war ramifications that are omitted from a public education. Practitioners may acknowledge the war and create space for students to explore its implications, understanding that the war holds different meanings for the current generation compared to previous generations, ultimately reframing these conversations as acknowledgements of culture, if not celebrations. Through building community with students to recognize and unpack the impacts of the war, higher education and student affairs practitioners may implement social justice informed education to better understand and support all underrepresented students.

\section{Limitations and Future Research}

Due to the low sample size and lack of heterogenous nature of the sample (i.e. homogenous sample consisting of only male, first-time freshman students), there were limitations to external validity. This limitation was due to the context in which participants of this study were recruited through voluntary means at a PWI largely comprised of male students who were first-time admitted freshmen. Furthermore, the lived experiences of participants from the current study may not fully capture experiences of 
Journal Committed to Social Change on Race and Ethnicity | Volume 7, Issue 1 | 2021

other VACS—-their admittance and arrival as first-time freshmen at a PWI, mainly comprised mostly of students from affluent backgrounds, suggests that they received family support and acceptance of family departure in search of personal growth and career pursuits. Future research on this population could benefit from recruiting a more diverse sample, including students with different gender identities, sexual orientations, socioeconomic statuses, or commuter experiences, or transfer experiences, to name a few.

\section{Conclusion}

This study aimed to understand how family impacts the college experiences of Vietnamese Americans. Several themes emerged including strong college-going expectations, less authoritarian parenting styles, modification and maintenance in household and cultural traditions, and construction of the Vietnamese American identity. Findings highlight the ways Vietnamese Americans conceptualize their experience of the intersection between family and college life-a phenomena, which effectively serves as a basis for future studies that may capture the complex narratives of Vietnamese Americans through examining other social factors. Higher education professionals, student affairs practitioners, and scholars may also utilize methods and findings from this research to better engage in inquiry, exploration, and discussion around the lived experiences of various students from diasporic cultural backgrounds, highlighting their own unique narratives as shaped by sociohistorical patterns in order to better understand, serve, and support them for a more equitable and inclusive higher education. 


\section{References}

Andrews, M., Squire, C., \& Tambokou, M. (Eds.). (2008). Doing narrative research. Sage Publications.

Bentley-Edwards, K.L., Agonafer, E., Edmondson, R., \& Flannigan, A. (2016). If I can do for my people, I can do for myself: Examining racial factors for their influence on goal efficacy for Black college students. Journal of College Student Development 57(2), 151-167. doi:10.1353/csd.2016.0018

Billing, T. K., Bhagat, R., Babakus, E., Srivastava, B.N., Shin, M., \& Brew, F. (2014). Work-family conflict in four national contexts: A closer look at the role of individualism-collectivism." International Journal of Cross Cultural Management 14(2), 139-159. doi:10.1177/1470595813502780

Chickering, A. W., \& Reisser, L. (1993). Education and identity (2 ${ }^{\text {nd }}$ ed.). Jossey-Bass.

Chhuon, V., \& Hudley, H. (2008). Factors supporting Cambodian American students' successful adjustment into the university. Journal of College Student Development, 49(1), 15-30. https://doi.org/10.1353/csd.2008.0005

Creswell, J. W. (2014). Research design: qualitative, quantitative, and mixed methods approaches (4th ed.). Sage Publications.

Erikson, E.H. (1963). Youth: Change and challenge. Basic books.

Fu, A., \& Hazel, M. (2014). My mother and me: Why tiger mothers motivate Asian Americans but not European Americans. Personality and Social Psychology Bulletin, 40(6), 739-749. doi:10.1177/ 0146167214524992

Han, M., Chou, V., Novotny, S., \& Nguyen, M. (2007). Parental control, intergenerational conflict, and depression in Southeast Asian American young adults. Poster presented at the $53^{\text {rd }}$ Annual Program Meeting of Council on Social Work Education (CSWE), San Francisco, CA.

Han, M., \& Lee, M. (2011). Risk and Protective Factors Contributing to Depressive Symptoms in Vietnamese American College Students. Journal of College Student Development 52(2), 154-166. doi:10.1353/csd.2011.0032

Hays, D. G., \& Singh, A. A. (2012). Qualitative inquiry in clinical and educational settings. The Guilford Press.

Ho, J., \& Birman, D. (2010). Acculturation gaps in Vietnamese immigrant families: Impact on family relationships. International Journal of Intercultural Relations, 34, 22-33. doi: 10.1016/j.ijintrel.2009.10.002

Jones, S. R., Torres, V., \& Armino, J. (2006). Negotiating the complexities of qualitative research in higher education: Fundamental elements and issues. Routledge.

Kibria, N. (1994). Household structure and family ideologies: The dynamics of immigrant economic adaptation among Vietnamese refugees. Social Problems, 41(1), 8196. doi: $10.2307 / 3096843$

Kim, B. S. K., Ahn, A. J., \& Lam, N. A. (2009). Theories and research on acculturation and enculturation experiences among Asian American families. In N.-H. Trinh, Y.C. Rho, F. G. Lu, \& K. M. Sanders (Eds.), Handbook of mental health and acculturation in Asian American families (pp. 25-43), Springer.

Lam, B. T. (2007). Impact of perceived racial discrimination and collective self-esteem on psychological distress among Vietnamese-American college students: Sense 
Journal Committed to Social Change on Race and Ethnicity | Volume 7, Issue 1 | 2021

of coherence as mediator. The American Journal of Orthopsychiatry, 77(3), 370 376. https://doi.org/10.1037/0002-9432.77.3.370

Libarios, E. D., Arriba, M., Lucas, C. M., Goto, K. K., \& Labrador, R. N. (2018).

Engaging Filipinx students in higher education to foster student success. Journal Committed to Social Change on Race and Ethnicity, 4(2), 1-37. https://doi.org/10.15763/issn.2642-2387.2018.4.2.1-37

Ma, Y. (2009). Family socioeconomic status, parental involvement, and college major choices-Gender, race/ethnic, and nativity patterns. Sociological Perspectives, 52(2), 211-234. https://doi.org/10.1525/sop.2009.52.2.211

Migration Policy Institute. (2018). Vietnamese immigrants in the United States. Migration Policy Institute. https://www.migrationpolicy.org/article/vietnamese-immigrantsunited-states-5

Museus, S. D. (2013). Unpacking the complex and multi-faceted nature of parental influences on Southeast Asian American college students' educational trajectories. The Journal of Higher Education, 84(5), 708-738. https://doi.org/10.1080/00221546.2013.11777306

Nguyen, P. V., \& Cheung, M. (2009). Parenting styles as perceived by Vietnamese American adolescents. Child Adolescent Social Work Journal, 26, 505-518. doi: 10.1007/s10560-009-0182-0

Nguyen, P. V., Leung, P., \& Cheung, M. (2011). Bridging help-seeking options to Vietnamese Americans with parent-child conflict and depressive symptoms. Children and Youth Services Review, 33, 1842-1846. doi: 10.1016/j.childyouth.2011.05.009

Palmer, R. T., \& Maramba, D. C. (2015). The impact of social capital on the access, adjustment, and success of Southeast Asian American College Students. Journal of College Student Development, 56(1), 45-60. doi:10.1353/csd.2015.0007

Pew Research Center. (2015). Education attainment of Vietnamese population in the U.S., 2015. Pew Research Center. http://www.pewsocialtrends.org/factsheet/asian-americans-vietnamese-in-the-u-s-fact-sheet/

Pham, V. H. (1994). Cultural Crossroads: The formation of Vietnamese American consciousness for the 1.5 generation. The Regents of The University of California.

https://oac.cdlib.org/view?docld=hb5x0nb45r\&brand=oac4\&doc.view=entire_text

Pinnegar, S. \& Danes, J. G. (2007). Locating narrative inquiry historically: Thematics in the turn to narrative. In D. Jean Clandinin (Ed.), Handbook of narrative inquiry: Mapping a methodology (pp.3-34). Sage Publications.

Pyke, K. (2000). 'The normal American family' as an interpretive structure of family life among grown children of Korean and Vietnamese immigrants. Journal of Marriage and Family 62(1), 240-255. doi: 10.1111/j.1741-3737.2000.00240.x

Saldaña, J. (2009). The coding manual for qualitative research. Sage Publications.

Sneed, J. R., Schwartz, S. J., \& Cross, W. E. (2006) A multicultural critique of identity status theory and research: A call for integration. Identity, 6(1), 61-84. doi: 10.1207/s1532706xid0601_5

Taub, D. J. (2008). Exploring the impact of parental involvement on student development. In Carney-Hall, K. C. (Ed.) Managing parents' partnerships: Maximizing influence, minimizing interference, and focusing on student success. 
Journal Committed to Social Change on Race and Ethnicity | Volume 7, Issue 1 | 2021

New directions for student services (pp. 15-28), Jossey-Bass. doi: $10.1002 /$ ss.272

Tingvold, L., Hauff, E., Allen, J., \& Middelthon, A.-L. (2012a). Seeking balance between the past and the present: Vietnamese refugee parenting practices and adolescent well-being. International Journal of Intercultural Relations, 36, 563574. doi: 10.1016/j.ijintrel.2012.03.004

Tingvold, L., Middelthon, A.-L., Allen, J., \& Hauff E. (2012b). Parents and children only? Acculturation and the influence of extended family members among Vietnamese refugees. International Journal of Intercultural Relations, 36, 260-270. doi: 10.1016.j/ijintrel.2011.03.005

Trahar, S. (2009). Beyond the story itself: Narrative inquiry and autoethnography in intercultural research in higher education. Forum: Qualitative Social Research, 10(1). http://nbn-resolving.de/urn:nbn:de:0114-fqs0901308

Trieu, M. M. (2016). Family Obligation Fulfillment Among Southeast Asian American Young Adults. Journal of Family Issues, 37(10), 1355-1383. https://doi.org/10.1177/0192513X14551174

U.S. Census Bureau. (2017). Highest educational levels reached by adults in the U.S. since 1940. https://www.census.gov/newsroom/press-releases/2017/cb1751.html

U.S. Census Bureau. (2020). U.S. Census Bureau Honors Asian American and Pacific Islander Heritage Month with key population and demographic statistics. https://www.commerce.gov/index.php/news/blog/2020/05/us-census-bureauhonors-asian-american-and-pacific-islander-heritage-month-key

Wartman, K. L., \& Savage, M. (2008). Parental involvement in higher education: Understanding the relationship among students, parents, and the institution. Association for the Study of Higher Education (ASHE) Higher Education Report, 33(6). doi: 10.1002/ache.3306

Yuan, S., Weiser, D.A., \& Fischer, J. L. (2016). Self-efficacy, parent-child relationships, and academic performance: A comparison of European American and Asian American college students. Social Psychology of Education, 19, 261-280. https://doi.org/10.1007/s11218-015-9330-x

Yeh, T.L. (2004). Issues of college persistence between Asian and Asian Pacific American students. Journal of College Student Retention, 6(1), 81-96. https://doi.org/10.2190/MG9G-76UR-7BUK-5JUW 